cédé, puisqu'ils n'avaient rien produit de solide, le disciple de Platon découvrit et démontra plus de vérités, executa plus de travaux scientifiques en un vie de soixante-deux ans, qu'après lui vingt siècles n'en ont pu faire," 1 \&c., \&c.

"Aristote est le premier qui ait introduit la méthode de l'induction, de la comparaison des observations pour en faire sortir des idées générales, et celle de l'expérience pour multiplier les faits dont ces idées générales peuvent être déduites."-ii. p. 515.

The late Mr. G. H. I.ewes, ${ }^{2}$ on the contrary, tells us " on a superficial examination, therefore, he [Aristotle] will seem to have given tolerable descriptions ; especially if approached with that disposition to discover marvels which unconsciously determines us in our study of eminent writers. But a more unbiased and impartial criticism will disclose that he has given no single anatomical description of the least value. All that he knew may have been known and probably was known, without dissection. .... I do not assert that he never opened an animal; on the contrary, it seems highly probable that he had opened many ...... He never followed the course of a vessel or a nerve; never laid bare the origin and insertion of a muscle; never discriminated the component parts of organs; never made clear to himself the connection of organs into systems." -(pp. 1 56-7.)

In the face of the description of the heart and lungs, just quoted, I think we may venture to say that no one who has acquired even an elementary practical acquaintance with anatomy, and knows of his own knowledge that which Aristotle describes, will agree with the opinion expressed by Mr. Lewes; and those who turn to the accounts of the structure of the rock lobster and that of the lobster, or to that of the Cephalopods and other Mollusks, in the fourth book of the "Historia Animalium" wiil probably feel inclined to object to it still more strongly.

Gn the other hand, Cuvier's exaggerated panegyric will as little bear the test of cool discussion. In Greece, the century before Aristotle's birth was a period of great in tellectual activity, in the field of physical science no less than elsewhere. The method of induction has never been used to better effect than by Hippocrates; and the labours of such men as Alkmeon, Demokritus, and Polybus among Aristotle's predecessors, Diokles, and Praxagoras, among his contemporaries, laid a solid foundation for the scientific study of anatomy and development, independently of his labours. Aristotle himself informs us that the dissection of animals was commonly practised ; that the aorta had been distinguished from the great vein; and that the connection of both with the heart had been observed by his predecessors. What they thought about the structure of the heart itself, or that of the lungs, he does not tell us, and we have no means of knowing. So far from arrogantly suggesting that he owed nothing to his predecessors, Aristotle is careful to refer to their observations and to explain why, in his judgment, they fell into the errors which he corrects.

Aristotle's knowledge, in fact, appears to have stood in the same relation to that of such men as Polybus and Diogenes of Apollonia, as that of Herophilus and Erasistratus did to his own, so far as the heart is concerned. He carried science a step beyond the point at which he found it; a meritorious, but not a miraculous, achievement. What he did required the possession of very good powers of observation; if they had been powers of the highest class he could hardly have left such conI "Histoire des Sciences Naturelles."-t. i. p. I30. 2 "Aristotie, a Chapter from the History of Science." spicuous objects as the valves of the heart to be discovered by his successors.

And this leads me to make a final remark upon a singular feature of the "Historia Animalium." As a whole, it is a most notable production, full of accurate information and of extremely acute generalisations of the observations accumulated by naturalists up to that time. And yet, every here and there, one stumbles upon assertions respecting matters which lie within the scope of the commonest inspection, which are not so much to be called errors as stupidities. What is to be made of the statement that the sutures of women's skulls are different from those of men; that men and sundry male animals have more teeth than their respective females; that the back of the skull is empty, and so on? It is simply incredible to me that the Aristotle who wrote the account of the heart, also committed himself to absurdities which can be excused by no theoretical prepossession and which are contradicted by the plainest observation.

What, after all, were the original manuscripts of the "Historia Animalium"? If they were notes of Aristotle's lectures taken by some of his students, any lecturer who has chanced to look through such notes, would find the interspersion of a foundation of general and sometimes mintute accuracy, with patches of transcendent blundering, perfectly intelligible. Some competent Greek scholar may perhaps think it worth while to tell us what may be said for or against the hypothesis thus hinted. One obvious difficulty in the way of adopting it is the fact that, in other works, Aristotle refers to the "Historia Animalium" as if it had already been made public by himself.

T. H. HUXLEY

ON THE NECESSITY FOR A NEW

DEPARTURE IN SPECTRUM ANALYSTS

$\mathrm{T}$ is now about a year since I gave an account of the results to which the final discussion of a complete set of photographs of the spectra of the metallic elements compared with the spectrum of the sun had led me.

The comparison was limited necessarily to the blue and violet portions of the spectrum, as photography was employed, and the methods since worked out by Capt. Abney for photographing the other regions were not then available. Of set purpose I limited it still more, as I wished to find the dernier mot in the present state of science regarding the coincidence of metallic with Fraunhofer's lines; and for this it was imperative to work on a large scale over a small region rather than on a small scale over a large one.

In point of fact, the work was limited to about the $\frac{7}{100}$ th part of the spectrum, and this small part was mapped on a large scale. A complete map of the spectrum on the scale adopted would be about half a furlong long. The work took time : including interruptions of one kind and another, some four years were expended on it.

I have elsewhere discussed at some length the concfusion which stared us in the face when all the work was brought to focus, but it is important that I should here dwell upon it for a moment, especially as it is now possible, perhaps, to state it with more terseness and clearness than one could at first, when the new conception thus forced upon us and its consequences were less familiar to one's mind. 
Simply, it amounted to this. The new work had made us acquainted with the fact that there were coincidences in the lines of metallic spectra of two perfectly distinct kinds.

The lines of one kind we could explain, on the hypothesis that the elements are truly elementary, by supposing that in the case, let us say, of coincident lines in the spectrum of iron and cobalt, the common line was due to an impurity either of iron in the cobalt or of cobalt in the iron. Most spectroscopic workers were of the true faith in this matter; they accepted the dicta of the chemist, and not only was the work which had shown how the phenomena observed might be thus explained received with favour, but no one, so far as I know, inquired whether there was any other "might be" in the matter. It is more than probable, however, that the future will have much to say on this very point; but with this set of coincidences $I$ am not dealing in this paper.

So much for the one set of coincidences.

The other set was as different as possible. In this category there was, on the impurity hypothesis, no possible explanation forthcoming without changing ground. In fact, the separation of the coincidences into two classes was brought about by this very circumstance, since all the coincidences which, in accordance with a general law established for a constant temperature some years before, could be attributed to impurity had, as a matter of fact, been eliminated from the maps at a prior stage of the investigation. Further, be it noted that all the photographs represented the work of similar temperatures, for they were all taken with electric arcs, for the production of which the same number of Grove's cells was used in all cases.

Since therefore these lines which were common to two or more spectra, could not be traced to impurities, what was their probable origin? Their number was so great that to attribute them to physical coincidences, and to rest and be thankful accordingly, would have been to take the very pith and marrow out of the science of spectrum analysis, which we have heard so often is based absolutely upon different substances giving us spectra with special lines for each. The matter then was worthy of serious investigation.

Using the analogy presented by the spectroscopic behaviour of known compounds when simplified by heat, a simple explanation of these common lines lay on the surface. This explanation is as follows :-

The temperature of the sun and the electric arc is high enough to dissociate some of the so-called chemical elements, and give us a glimpse of the spectra of their bases, just as in the case of the various salts of calcium there is a temperature which just allows us to get a glimpse of a line indicating the metal calcium common to them all.

Hence it was allowable to term the coincident lines of the second order "basic lines," since they might point to the existence of a base common to the substances in the spectra of which they appeared. Davy, before he discovered potassium, used, as I have since found, the word "basic" to express the same idea.

I propose in the present paper to refer to some of the facts collected along one line of work to which my subsequent studies of these lines has led me, with a view to show that their true basic nature can now no longer be open to doubt.

Naturally the first thing to do was to see if these basic lines varied in their behaviour from other lines of spectra taken at random. Supposing them to represent mere chance coincidences- "physical coincidences," as they have been called, or again, lines so near together that our means cannot separate them-there is no reason why they should vary together when the temperature is changed; while, if they be truly basic, they must vary with temperature. Further, they must vary in such a way that other conditions being equal, they shall become stronger when the temperature is increased, and become fainter when the temperature is reduced.

Now what was the best mode of attacking this problem? I was unable to see a more expeditious one than that presented to us by the sun. The following consideration will show how we might hope for help in this quarter.

We are accustomed to say that the sun is surrounded by an enormous atmosphere, and that this atmosphere has in it the vapours of metals, such as iron, magnesium, \&c., with which metals we are familiar on this planet. This statement has been based on the near agreement presented by the places of the lines in the spectrum of the substances as studied in our laboratories and the Fraunhofer lines themselves. The matching of these spectra is nothing like so perfect, and the conclusion drawn, therefore, is nothing like so firmly based, as is generally imagined; but this point need not occupy our attention at present; what it is important for us to bear in mind is this: whatever be the chemical nature of this atmosphere, it will certainly be hotter at bottom-that is, nearer the photosphere-than higher up. Hence, if temperature plays any part in moulding the conditions by which changes in the resulting spectrum are brought about, the spectrum of the atmosphere close to the photosphere will be different from that of any higher region, and therefore from the general spectrum of the sun, which practically gives us the summation of all the absorptions of all the regions from the top of the atmosphere to the bottom.

Now as a matter of fact we have the opportunity, when we observe the spectrum of a sun-spot or a prominence, of determining the spectrum of an isolated mass of vapours in the hottest region open to our inquiries, and seeing whether it is like or unlike the general spectrum of the sun. What then are the facts?

It is as unlike as possible : the intensities of the lines are inverted to a wonderful extent. More than this there is a constant difference between the spectra of sun-spots and the spectra of metallic prominences, though we see these phenomena generally at about the same niveau in the sun's atmosphere. This may arise from the fact that in the case of the spots we deal generally with a greater thickness of the vapours.

To get the best idea of this inversion I have prepared maps of the spectra of the chief chemical substances showing the behaviour of the various lines under the various conditions. The result is very striking; indeed it is striking to quite an unexpected degree. The whole character of the spectrum of iron, for instance, is changed when we pass from the iron lines seen among the Fraunhofer lines to those seen among the spot- 
and storm-lines; a complex spectrum is turned into a simple one, the feeble lines are exalted, the stronger ones suppressed almost altogether.

Since then the spectra of spots and prominences are confessedly the spectra of the hottest region of the sun available to our inquiries, we can test the nature of the basic lines by seeing how they behave when we pass from the general solar to these special solar spectra.

With special reference to this point I have brought together the various observations which have been recorded of the lines visible in solar disturbances at the sun's limb, and those observed to be widened, brightened, or otherwise modified in the spectra of solar spots.

The finest series of observations of this kind that we possess is that collected by Prof. Young near the time of the last maximum of sun-spots, during his stay at Sherman, at a height of 8,000 feet. The result which stares us in the face when we examine the work done by Young is most striking; but although his observations of the chromospheric lines extend over the whole visible spectrum, the list of lines in the solar spots is limited to the less refrangible region; we must therefore limit the discussion to this region.

As a basis for the discussion, I have used the lines given in Thalén's admirable tables, comparing them with those shown in Ångström's map, and indicating the intensities of the lines which are given in the tables, and which particular line occurs in the map only. A glance then shows which line is seen in spots and prominences, and how it is affected. In short we have in one view, for each metallic substance, exactly what happens to the lines of that substance--which lines are not touched; those which are visibly affected both in spots and storms, or those recorded in one table and not in the other.

Taking all the lines included in the discussion, the following statistics will show how they are distributed:-

Total number of lines in Thalén's list and map

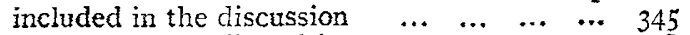

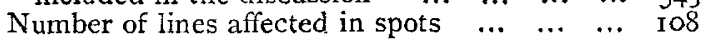

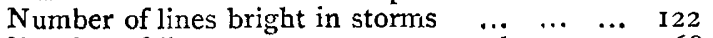

Number of lines common to spots and storms 68

Number of lines seen in neither spots nor storms 183

So much for the list of lines as a whole. It is also necessary to show the number of lines assigned to each metal, and those among them which occur in both spots and storms, or only in one or the other.

\begin{tabular}{|c|c|c|c|c|c|c|}
\hline \multirow{2}{*}{\multicolumn{2}{|c|}{ Metal. }} & \multirow{2}{*}{$\begin{array}{l}\text { Number } \\
\text { of Lines. }\end{array}$} & \multirow{2}{*}{$\begin{array}{c}\text { Number of } \\
\text { lines } \\
\text { common } \\
\text { to spots } \\
\text { and } \\
\text { storms. }\end{array}$} & \multicolumn{2}{|c|}{$\begin{array}{l}\text { Number of lines due } \\
\text { to }\end{array}$} & \multirow{2}{*}{$\begin{array}{l}\text { Unaf- } \\
\text { fected. }\end{array}$} \\
\hline & & & & Spots. & Storms. & \\
\hline $\begin{array}{l}\text { Sodium } \\
\text { Magnesium } \\
\text { Barium } \\
\text { Calcium } \\
\text { Strontium } \\
\text { Nickel... } \\
\text { Cobalt ... } \\
\text { Manganese } \\
\text { Cadmium } \\
\text { Chromium } \\
\text { Titanium } \\
\text { Iron... }\end{array}$ & $\begin{array}{l}\cdots \\
\ldots \\
\ldots \\
\ldots \\
\cdots \\
\cdots \\
\cdots \\
\ldots \\
\cdots \\
\cdots\end{array}$ & $\begin{array}{r}8 \\
4 \\
23 \\
25 \\
18 \\
12 \\
19 \\
16 \\
15 \\
14 \\
87 \\
104\end{array}$ & $\begin{array}{r}4 \\
3 \\
1 \\
7 \\
0 \\
1 \\
3 \\
2 \\
0 \\
3 \\
\text { I I } \\
33\end{array}$ & $\begin{array}{r}6 \\
4 \\
3 \\
15 \\
0 \\
3 \\
3 \\
3 \\
0 \\
3 \\
18 \\
50\end{array}$ & $\begin{array}{r}6 \\
3 \\
7 \\
10 \\
0 \\
2 \\
3 \\
6 \\
0 \\
5 \\
18 \\
62\end{array}$ & $\begin{array}{r}0 \\
0 \\
14 \\
7 \\
18 \\
8 \\
16 \\
9 \\
15 \\
9 \\
62 \\
25\end{array}$ \\
\hline \multicolumn{2}{|c|}{ Iron... $\quad .}$. & 345 & 68 & Ic 8 & 122 & 183 \\
\hline
\end{tabular}

It will be seen that the ratio between the affected and unaffected lines is very variable. What strikes one, indeed, is the wonderful irregularity in the behaviour of the various lines; there is no relation, for instance, between the widening of the lines in the spots and their appearances in the prominences.

It may here be asked, "But what has this to do with basic lines?" I answer, it would have nothing to do with basic lines if Thalen had not observed them; but in his observations, which are the ne plus ultra of spectroscopic accuracy, he came across them abundantly. The basic lines therefore have the great advantage of not being new. Among the 345 lines given by Thalén are 18 with identical readings in two spectra. They are, therefore, the exact equivalents of those lines which I have found to be basic in work on another part of the spectrum.

Now, for the reasons above given, if my explanation of their basic character be the correct one, then we should expect a considerable development of these lines in the spectrum of the hottest regions of the sun, which spots and storms enable us to study apart from the absorption going on at higher levels.

It is not too much to say that the result of this inquiry settles this question in the most conclusive way. What does come out in the strongest manner is the following very remarkable fact.

The only constant thing in the tables employed in the inquiry is, that these basic lines are always widened in the spots. However badly the brighter lines of a chemical substance, taken as a whole, may be represented amongst the spot lines, as the basic lines, among these which are often of the second or third order of intensity and sometimes even of the fourth, are never absent. The same fact holds almost equally true with regard to the storms.

The following comparison of Thalén's basic lines with those seen by Young in solar spots and storms shows this result :-

\begin{tabular}{|c|c|c|c|c|c|c|c|}
\hline \multicolumn{5}{|c|}{ Thalén. } & \multicolumn{3}{|c|}{ Young. } \\
\hline \multirow{2}{*}{ Wave-length. } & \multirow{2}{*}{\multicolumn{2}{|c|}{ Common to }} & \multirow{2}{*}{\multicolumn{2}{|c|}{ Intensity. }} & Spots. & \multicolumn{2}{|c|}{ St orms. } \\
\hline & & & & & $\begin{array}{l}\text { Widen- } \\
\text { ing. }\end{array}$ & $\begin{array}{l}\text { Fre- } \\
\text { quency. }\end{array}$ & $\begin{array}{c}\text { Bright - } \\
\text { ness. }\end{array}$ \\
\hline $5207 \cdot 6$ & $\mathrm{Fe}$ & $\mathrm{Cr}$ & 3 & $\mathbf{I}$ & 4 & 10 & 6 \\
\hline $5203^{\circ} 7$ & $\mathrm{Fe}$ & $\mathrm{Cr}$ & 3 & I & 4 & 10 & 6 \\
\hline $5340 \cdot 2$ & $\mathrm{Fe}$ & $\mathrm{Mn}$ & 2 & 3 & 2 & I & 2 \\
\hline $6064 \cdot 5$ & $\mathrm{Fe}$ & $\mathrm{Ti}$ & 2 & 2 & 3 & 5 & 2 \\
\hline $5661 \cdot 5$ & $\mathrm{Fe}$ & $\mathrm{Ti}$ & 3 & I & 4 & 15 & 2 \\
\hline $5403^{-1}$ & $\mathrm{Fe}$ & $T i$ & 2 & 3 & 4 & 5 & 3 \\
\hline $5396 \cdot 1$ & $\mathrm{Fe}$ & $\mathrm{Ti}$ & 2 & 2 & 7 & 4 & 2 \\
\hline $535^{2} 4$ & $\mathrm{Fe}$ & $\mathrm{Co}$ & 4 & 3 & 2 & 4 & 2 \\
\hline $5265 \cdot 8$ & $\mathrm{Fe}$ & Co & 2 & 3 & 2 & IO & 4 \\
\hline $5168 \cdot 3$ & $\mathrm{Fe}$ & $\mathrm{Ni}$ & 3 & 5 & 4 & 40 & 30 \\
\hline $5166 \cdot 7$ & $\mathrm{Fe}$ & $\mathrm{Mg}$ & 2 & I & 2 & 30 & 20 \\
\hline 56814 & $\mathrm{Fe}$ & $\mathrm{Na}$ & 3 & 3 & 3 & 2 & $\mathbf{I}$ \\
\hline $612 I \cdot 2$ & $\mathrm{Co}$ & $\mathrm{Ca}$ & I & 3 & 4 & 5 & 3 \\
\hline $5601 \cdot 7$ & $\mathrm{Ca}$ & $\mathrm{Fe}$ & 4 & I & 2 & & \\
\hline $5597^{*} 2$ & $\mathrm{Ca}$ & $\mathrm{Fe}$ & 3 & I & 2 & & \\
\hline $5^{8} 56.5$ & $\mathrm{Ca}$ & $\mathrm{Ni}$ & 3 & 4 & 2 & & \\
\hline $5425^{\circ} \mathrm{O}$ & $\mathrm{Ba}$ & $\mathrm{Ti}$ & 3 & 3 & 4 & & \\
\hline $6449^{\circ} 0$ & $\mathrm{Ca}$ & $\mathrm{Ba}$ & 2 & 3 & 2 & & \\
\hline
\end{tabular}

So far as my own knowledge of these matters goes, I can imagine no severer test to apply to the hypothesis that the basic lines in the above table are produced by the 
dissociation of the metals to which the lines are common in this case chiefly the metals of the iron group-in the hottest region of the sun, and to my mind the proof is conclusive that at that temperature we have a mixed mass of vapours. in which the base is more predominant than the so-called chemical elements to which that base is common.

But although thrhold that this is the most conclusive test to apply; it is not the only one which the sun affords us

We have every reason to believe that there is a considerable difference in the temperature of the spot-and storm-stratum when it is absolutely quiescent and cut off from all visible action from below, and again when it is riddled with convection currents of the most tremendous character-in other words that its temperature at the sunspot maxima and minima is not the same. Hence we may imagine that the difference of temperature will affect the basic lines especially, and that they will be stronger at one period of the sun-spot curve than at another.

I limit myself for the present to the statement that this comparison has also been made to a certain extent, and that the result of it is entirely in harmony with what has gone before, so far as the observations go, but more spots must be obsenved before a complete discussion is possible. This, however, is certain, that basic lines widened at Sherman in 1872 were not observed widened at Greenwich in 1877 , or at Kensington in the spots which appeared last month.

I for my part, then, am perforce driven by the stern logic of facts to the conclusion that these "basic lines" are not accidental; are not "physical coincidences;" and do not owe their origin to impurities; but that their appearance in two or more spectra is dependent upon high temperature merely.

The original statement, then, that the spectrum of each element consists only of lines special to that element, is found to be insufficient when the highest temperatures and the greatest dispersions are employed, and a "higher law" bas to be introduced to bring the statements of the textbooks into harmony with the facts.

The dissociation of the elements of the iron group at the highest temperatures we can command and in the sun, is a cause by which this fact can be explained, if we accept the law of continuity, and reason on well based analogies.

This, of course, constitutes a new departure in spectrum analysis, whatever its bearing may be found to be upon Chemical Philosophy, when that subject is again studied as it once was.

To those who follow the line of reasoning on such a subject which the spectroscope provides us with, and even to those who admit the cogency of the conclusions, it will be astonishing that such a result has been arrived at in such an indirect way; there are, however, many minds so constituted that they will prefer to endow matter with any number of undreamt of qualities before they will accept such a solution.

But for all that, when the facts are well considered by competent authorities, it will, I think, be granted that an inorganic evolution is already glimpsed, in the study of which we shall not be baffled by any "breaks in strata." J. NORMAN LOCKYER

\section{MIND IN THE LOWER ANIMALS}

Mind in the Lower Animals in Health and Disease. By W. Lauder Lindsay, M.D., F.R.S.E., F.L.S., \&c. (London: C. Kegan Paul and Co., I879.)

R. LAUDER LINDSAY has long been known as a contributor to periodical literature in the province of comparative psychology. The work which he now publishes with the above title clearly represents a great amount of labour. It is in two large octavo volumes which together present somewhat over 1,000 pages, and contain references to the writings of about 200 authors. It is furnished with an excellent index and a bibliography. The latter, we are told, is "confined to works consulted by the author," and "almost exclusively to those published in Britain and in the English language." The work is also furnished with a long "enumeration of the animals whose character and habits form the basis of the author's generalisations." The list includes 908 species belonging to 516 genera, both the popular and the scientific names heing in every case supplied.

In so extensire a work by so well-known a man there is, as we should expect, a great deal that is both of interest and value. Particularly in this connection may be pointed out his compilation and digestion of facts regarding the psychology of savages as contrasted with that of animals, and also many of his observations on the insanity of animals as compared with the insanity of man. His chapters on "General Adaptiveness and "The Use of Instruments" also deserve, on the whole, to be commended.

But while we welcome a book-and especially a popular book-the leading object of which is to prove the kinship of animal intelligence to human, it is impossible not to regret the occurrence of certain faults which the exercise of a little more judgment might have obviated. In the first place the work is painfully diffuse. Whole pages, and even chapters, might with advantage have been omitted, while there are but few chapters which might not, with equal advantage, have been considerably condensed. Those, for instance, on "Faults of Terminology" "Animal Reputation," "Responsibility of Animals," and others, appear utterly useless. Whether or not it is accurate to call the lower animals "dumb," "lower," $\& c$. , and whether or not the "reputation" of a dog suffers from the use of such terms as "dogging," "hounding," "cat and dog life," \&c., and whether or not any one is so foolish as to suppose that a smuggler's dog is morally responsible for a smuggler's acts; whether or not these things are so, they are certainly not of sufficient importance to demand lengthy discussion. Again, such statements as the following are quite superfluous, at least out of a nursery-book:-

"While the dog barks, bites, growls, howls, whines, sniffs, and snarls; the horse neighs, kicks, stamps, paws, snorts, champs, lashes its tail ; the cat purrs, scratches, hisses, mews ; cattle low, butt, gore, bellow ; the elephant trumpets, roars, screams; the sheep and goat bleat; the ass brays, the cock crows, and the hen clucks and cackles."

This is all quite true, but it is not new; and the same remark is applicable to pages and pages of both volumes. In short, unlimited diffusiveness is the worst fault of the book. The next worst fault is that of presenting alleged 